\title{
Navigating academia during the COVID-19 pandemic: Can you do it all?
}

\author{
Abha Rai, Ph.D., MSW ${ }^{1}$ and ${ }^{\text {Kisten E. Ravi, Ph.D., LMSW }}{ }^{2}$ \\ ${ }^{1}$ School of Social Work, Loyola University Chicago, Chicago, IL, USA \\ ${ }^{2}$ College of Social Work, The University of Tennessee-Knoxville, Knoxville, TN, USA
}

Received 01 October 2020

Accepted for publication 18 November 2020

Published 18 December 2020

\begin{abstract}
The goal of this reflection paper is to draw from our own experiences of starting new tenure-track faculty positions in social work departments amid a global pandemic. By drawing from our experiences, we hope to reflect on strategies and resources utilized. By discussing our approach, we endeavor to provide support to other academics across the world. We believe these resources and strategies will be useful as we continue to live in the "new normal".
\end{abstract}

Keywords: social work, COVID-19, tenure-track, academia, early career, faculty

\section{COVID-19 and academia}

As new assistant professors at universities in the Midwest and Southeastern region of the United States, the year 2020 has been no less than a roller coaster ride. Beginning from defending our dissertations virtually, to attending a zoom graduation and ultimately starting a new tenure-track position amid a pandemic, has been an interesting experience. While this experience has provided unique learning opportunities related to research and teaching, it has occasionally been trying. By sharing our teaching and research reflections, we summarize some of the best practices that we benefitted from in our first semester. We will focus on our experiences and the strategies that helped us overcome the barriers we faced. Our experiences will be helpful for international social work educators, both early and mid-career. Throughout this commentary, we describe our strategies with the hope for other international social work educators to utilize them as useful resources, as well.

\section{Our positionalities, roles, and preparation for the autumn/fall semester}

We are in two distinct spaces in our lives. Both authors classify themselves as social work practitioners, researchers and educators. The first author is a international social worker with experience working in community-settings in India and the United States. The second author is a licensed social worker whose experience is with children and families primarily within the school setting.

Our positionalities impacted our experiences during the pandemic. The frequent immigration policy changes under President Trump in the US led to rampant modifications in the eligibility for obtaining and maintaining work visas (Anderson, 2020; White House, 2020); increasing stress. The first author who is an immigrant, in addition to navigating a new job, was constantly weary of these immigration policy changes impacting her work visa. She was also overwhelmed about having to care for her family remotely due to the travel ban. The second author is a mother to a 5-year old boy who had to sell and buy a new home during the pandemic to ensure she could arrive at her new home to start her son's school virtually and her new job. The planning, packing, and moving is never easy. The challenges were heightened because of the added safety precautions and concerns during this pandemic. Despite being at two different types of schools of social work, Research 1 [very high research activity doctoral university], and Research 2 [high research activity doctoral university], as classified by the Carnegie classification of institutions of higher education (Indiana University Center for 
Postsecondary Research, 2017), our experiences about navigating academia were not disparate.

\subsection{Getting the publications}

In academia we have often heard fellow academics discern that publications are a valuable currency (Fogarty, 2009; Ye, 2019). Additionally, in speaking with mentors and other faculty at our respective institutions, we were explained the importance of frontloading publications. Frontloading publications refers to submitting maximum number of publications during early years of one's career to ease out the expectations of tenure. Following the advice, we decided to collaboratively make a plan to gather this currency. The National Center for Faculty Development and Diversity (NCFDD, n.d.) has a gamut of resources that can support planning for the semester and academic writing. Using their approach, we ensured that despite the mayhem that the pandemic brought into our lives, we spent at least 30 minutes, if not more, writing every day. This type of writing style is also known as 'snack writing' which translates into writing for short periods of time each day or several times a day as compared to writing for longer durations (Murray, 2014). While this style may be relevant for scholars at any stage, it can especially be helpful for early career scholars who may be trying to actively plan and build their scholarship. To support each other, we served as peer mentors and accountability partners to ensure that we met our own individual goals. In doing so, by the summer of 2020 , we were able to submit half a dozen publications each.

At times, our days were long, which involved caring for a parent or family member, childcare, and stocking up on supplies due to the ongoing challenges of the pandemic. But whatever the day looked like, we tried our best to incorporate our writing time. Some days were better than others with more uninterrupted writing time. In addition to working on publications, our task was to also find local community partners and collaborators at our new institutions. That is where we began our journey of being in an unprecedented number of zoom meetings. Like others, we were inundated with emails, responses, and had a long list of follow-ups (which we are updating even right now) while navigating how to get a head start with research virtually.

For me (AR), it was helpful to build on existing relationships and tap into the connections that the university and research centers already had. I made it a point to set up at least 2-3 meetings a week with potential collaborators. I (KR) took a similar approach however, it occurred after I had relocated, and my family and I settled into our new house. My faculty mentor and a staff member in the social work field office helped facilitate connections with other faculty on campus and community partners. Collaboration also relates to getting our publication expectations for tenure. Writing in teams and with collaborators who are as motivated as I am has helped me stay productive while sharing the load of being on manuscripts and research projects with collaborators. Moreover, considering it takes time to develop relationships with community partners, we actively sought to gain secondary data access that we could analyze and use to promptly publish studies. Both of us sought the guidance and mentorship of faculty mentors at our schools to strategically develop a scholarship plan which can be beneficial for early career scholars.

\subsection{Teaching virtually}

As assistant professors, we are also educators. In my (AR) university, being educators who can provide students a pathway to be successful is valued. However, there are several challenges with teaching online. We will detail some of our best practices that helped us organize and structure our classes.

We began by meeting other instructors who had taught the course previously to obtain materials, clarify assignments, and request any available supplemental material. We were fortunate to have support from others at our universities. Despite the support, we still had the daunting task of adapting the content to an online course, which is how our universities decided to offer classes this semester or allowed faculty to decide. Central to both our teaching philosophies is active engagement of students (Fink, 2013). Therefore, we thoughtfully and critically examined how students could best engage with the course content. This led us to look outside of the course material and identify supplemental videos, podcasts (Gaden, 2009), design assignments, and simulation activities that could allow students to take on an active role in their own learning. Both our universities promote active learning in the classroom, and, evidence indicates that this style of learning promotes the acquisition of higher level of skills and capabilities among students (Gifkins, 2015; Wenham, 2020). To further engaged learning, our summer was also filled with a series of trainings designed to structure online classes and make them more accessible.

Zoom fatigue is real! To minimize that, we both constructed a flipped classroom (Nilson, 2016). In this style of classroom our focus was on providing engaged learning opportunities rather than lecturing. Both of us briefly reviewed the content that students had read and listened to via their lecture recordings during the previous week. Our classes included both a synchronous and asynchronous component. The synchronous sessions lasted approximately an hour and a 
half. Asynchronously, students were expected to engage with the week's content through readings, lectures, discussion posts etc. We spent time clarifying the material during the virtual class, posed discussion questions, and used the breakout room feature on zoom for small group activities.

Individually, each of us followed some best practices that helped us ensure that we remained kind to our students and also regularly checked-in with them. For example, I (AR) had students fill out a questionnaire at the beginning of the semester, allowing them to share their unique needs and expectations from the course and me. A few weeks ago (in October 2020), I also completed a midsemester evaluation, where I reassessed their needs and how I could better support them. Each time I asked students to take a survey, I made it a point to share the class's needs with everyone during the synchronous session and follow-up with specific students to address individual needs, as necessary. In addition to office hours, I also designed "non-office hours" to provide mentorship with student careers and research.

Prior to classes, I (KR) sent an introductory email to the students in my course asking them about their feelings about our class starting, any concerns they have related to the course being conducted remotely, and how I can best support them. At the beginning of each synchronous session, I send the students a link to a live word cloud where I ask them to write words describing how they feel as a check-in, providing an opportunity for them to discuss their feelings. Additionally, since I am utilizing a flipped classroom approach, I created a google spreadsheet for students to anonymously write any questions about the material I addressed in class, if they do not feel comfortable asking questions in class.

\subsection{Getting to know your colleagues and staying involved}

Starting a new job comes with new excitement and adjustment. A crucial component of beginning a new position is getting to know your colleagues. This was definitely an area of challenge for us, considering we started our positions remotely, juggling several other responsibilities we had, professionally and personally. I (AR) proactively reached out to my colleagues, with those of whom were available to set up zoom "meet and greets". This approach allowed me to get to know my colleagues while also allowing them an opportunity to get to know me. I (KR) both received invitations from my colleagues to connect over Zoom as well as connected with new colleagues, whom I hoped to collaborate with or learn from about their experiences as a tenure-track professor.

\section{Conclusion}

It was important to both of us to incorporate a daily selfcare routine (Mental Health America, 2020) and more expansive regimens through our first semester. Self-care can look different for all of us, but consistent self-care is beneficial. A fine balance of being kind to ourselves, recognizing the need to slow down and take breaks was beneficial to us. For instance, I (AR) ensured that I maintained a healthy workout regimen. Running has always helped me clear my head and get my ideas together. I continued to follow that through this pandemic as well. I (KR) prioritized sleep by not going to bed later than $11 \mathrm{pm}$ on weeknights and reading something non-academic to relax. Following this sleep hygiene routine, helped ensure quality rest which positively affected my work and relationships. Our earnest attempt through this reflective paper has been to share some of our personal experiences and learning opportunities, along with strategies we used to overcome our barriers. While we believe that navigating academia during the COVID-19 pandemic can be difficult, specific strategies, collaborations and support systems have helped us manage our workload as well as other commitments. We hope these strategies serve as resources and inspiration to other academics who may be struggling with doing it all in this "new normal" called COVID-19.

\section{References}

Anderson, S. (2020, October 7) Trump administration issues two new rules to restrict $\mathrm{H}-1 \mathrm{~B}$ visas. Forbes. https://www.forbes.com/sites/stuartanderson/2020/10/07/t rump-administration-issues-two-new-rules-to-restrict-h1b-visas/?sh=298fd1da5120 (Accessed: 23 November 2020).

Fink, L. D. (2013) Creating significant learning experiences: An integrated approach to designing college courses. New Jersey, Hoboken: John Wiley \& Sons.

Fogarty, T. (2009) 'Show Me the Money: Academic Research as Currency', Accounting Education, 18(1), pp. 3-6.

Gaden, G. (2009) 'Podcasting: Thinking about new opportunities for pedagogy and activism', Thirdspace, 9(1). Available at: https://journals.sfu.ca/thirdspace/index.php/journal/article /view/291/296 (Accessed: 23 November 2020).

Gifkins, J. (2015, October 8) What is 'active learning' and why is it important? E-International Relations. Available at: https://www.e-ir.info/2015/10/08/what-is-activelearning-and-why-is-it-important/ (Accessed: 22 November 2020). 
Indiana University Center for Postsecondary Research (2017) Basic classification description. Available at: https://carnegieclassifications.iu.edu/classification_descri ptions/basic.php (Accessed: 22 November 2020 ).

Mental Health America (2020) Taking good care of yourself. Available at: https://www.mhanational.org/taking-goodcare-yourself (Accessed: 22 November, 2020 ).

Murray, R. (2014) 'Snack' and 'Binge' writing: editorial for Journal of Academic Development and Education', The Journal of Academic Development and Education, (2), pp. $5-8$

National Center for Faculty Development and Diversity (n.d.) About the National Center for Faculty Development and Diversity. Available at: https://www.facultydiversity.org/about-us (Accessed: 22 November 2020).

Nilson, L. (2016) Teaching at Its Best: A Research-Based Resource for College Instructors. $4^{\text {th }}$ edn. New Jersey, Hoboken: John Wiley \& Sons.

Wenham, T. (2020, April) 9 benefits of active learning (and why your college should try it). Nureva. Available at: https://www.nureva.com/blog/education/9-benefits-ofactive-learning-and-why-your-college-should-try-it (Accessed: 21 November 2020).

White House (2020, June 22) Proclamation suspending entry of aliens who present a risk to the U.S. labor market following the coronavirus outbreak. Available at: https://www.whitehouse.gov/presidentialactions/proclamation-suspending-entry-aliens-presentrisk-u-s-labor-market-following-coronavirus-outbreak/ (Accessed: 21 November 2020).

Ye, Y. (2019) Publication: a universal currency in academia. Available

at: https://socialsciences.nature.com/posts/54635publication-a-universal-currency-in-academia (Accessed: 22 November 2020). 